\title{
Proceedings
}

\section{Manipulating Mammal Herbivory in South Patagonia Forests: Effects on Plant Species Assemblage, Survival and Short-Term Growth Response of Nothofagus antarctica Seedlings ${ }^{+}$}

\author{
Rosina Soler *, Gimena Bustamante and Ana Paula Blazina \\ Centro Austral de Investigaciones Científicas (CADIC), CONICET. Houssay 200 (9410) Ushuaia, Tierra del \\ Fuego, Argentina; rosisoler@yaho.com.ar \\ * Correspondence: rosisoler@yaho.com.ar; Tel.: +54-2901-44310-168 (R.S.) \\ + Presented at the 1st International Electronic Conference on Forests, 15-30 November 2020; \\ Available online: https://sciforum.net/conference/IECF2020
}

Published: 25 October 2020

\begin{abstract}
Livestock browsing and large wild herbivores in forested areas have been perceived as conflicting with silviculture and forest conservation for long time. However, silvopastoral systems in native forests entail livestock manipulation in space and time, to reduce negative impacts on forest structure and dynamics. In 2014, we established eight $15 \times 15 \mathrm{~m}$ fences (and the respective control plots with browsing) in four Nothofagus antarctica (ñire) silvopastoral sites in Tierra del Fuego Island, to protect tree seedlings and vegetation from cattle and guanaco browsing. After five growing seasons, the exclusion treatment favored regeneration of nire by reducing browsing pressure while increasing seedling growth rate, though the effect on seedling survival was weak. Soil moisture increased while soil compaction decreased over years in all fields, though the fences effect was weak. Palatable forbs (e.g., Taraxacum sp., Osmorhiza sp.) and grasses (e.g., Agrostis sp., Bromus unioloides) increased much more in abundance and height than ñire seedlings within fences. Thus, the use of exclusion treatments to manipulate browsing impact enhance short-term growth of ñire regeneration in south Patagonia forests used for cattle production. However, a negative effect by competing understory vegetation in fences probably also occur in the long term.
\end{abstract}

Keywords: forest management; natural regeneration; plant-plant interaction; silvopastoral use

\section{Introduction}

Native and exotic herbivores directly (through consumption) and indirectly (by modifying nutrient availability and interspecific relationships) modify the composition of plant communities [1, $2,3]$. The interaction between tree recruitment - livestock is one of the most controversial plant-animal interactions in silvopastoral systems (SPSs). In temperate North American SPSs [4] and Asutralia [5], although cattle feed mainly on grasses, young and adult trees are also consumed, and in this case a strong limitation for the natural regeneration has been recorded. However, the type and magnitude of livestock impact on forest ecosystems is determined by livestock type, grazing regime, and also presence of native ungulates [6,7].

The complete exclusion of wild and/or domestic ungulates by means of fencing is one of the most frequent practices [7] to facilitate tree regeneration or restoring degraded forests. However, some productive schemes (e.g., SPSs) seek to manage the animal density in time and space to reduce the negative impacts on forest structure and dynamics [8,9]. But few studies jointly evaluate the dynamics of tree recruitment and understory vegetation, the benefits (e.g., growth and survival) and the compromises (e.g., competition) that could be obtained from the regulation exerted by native 
ungulates and/or livestock through the consumption of plant material. In this study we evaluate the effect of herbivore exclusion on survival and short-term growth response of $N$. antarctica seedlings, as well as the effect on plant species assemblage.

\section{Materials and Methods}

The study was conducted in two farms located at the central area of Tierra del Fuego Island, Argentina. Within each farm, we selected two N. antarctica forest $(\sim 2$ ha size each one) used for livestock production and established permanent fences $(15 \times 15 \mathrm{~m}$ size) with three exclusion treatments: (i) overall exclusion ( $2.50 \mathrm{~m}$ high) to avoid entry of all types of herbivores, (ii) livestock exclusion (1.30 $\mathrm{m}$ high) to allow the entry of native herbivores (Lama guanicoe) only, and (iii) grazing area without fencing (control). Within each treatment, we established 5 plots of $0.6 \mathrm{~m}^{2}(3 \times 0.20 \mathrm{~m})$ randomly distributed and separated by at least $2 \mathrm{~m}$ from each other $(3 \times 3 \times 3, \mathrm{n}=27$ per farm). Tree seedlings $(<30 \mathrm{~cm}$ height $)$ were identified and quantified on each plot. We also recorded the seedling height, age, and damage (drought, browsing, undamaged). As each seedling was spatially identified on the plots $(\mathrm{x}, \mathrm{y})$, we then measured them annually during four consecutive summer seasons (20162019). Simultaneously, we established 5 transects (10 m long) associated to the previous plots, to assess the richness and abundance of vascular plant species (dicots, monocots and ferns) in each treatment. We used the point intersection method [10] to survey the presence of each plant species at $20 \mathrm{~cm}$ intervals (50 sampling points per transect). Vascular plants were identified at species level and differentiated by native or alien species. Then, these data were summarized for each treatment, by calculating the mean species richness and the mean vegetation cover per plot [10,11]. We also measured understory height at 5 points on the understory transect. The data was analyzed using two-ways ANOVAs $(\mathrm{p}<0.05)$, considering as main factors: the site (farm) and exclusion treatments for tree recruitment variables; and the year and exclusion treatments for understory vegetation. Also, the Tukey post-hoc test was used for the mean comparison.

\section{Results and Discussion}

Soil moisture increased while soil compaction decreased over years in all study sites (Fig. 1). But contrary to expectations, the animal exclusion treatments did not significantly modify the soil compaction. Rather, it seems to be a general effect at the site level where the effects of time were similar among all treatments. On the other hand, these two variables are naturally correlated [12] and this was evident in 2017 when soil moisture increased (due to rainfall) and soil compaction was reduced.

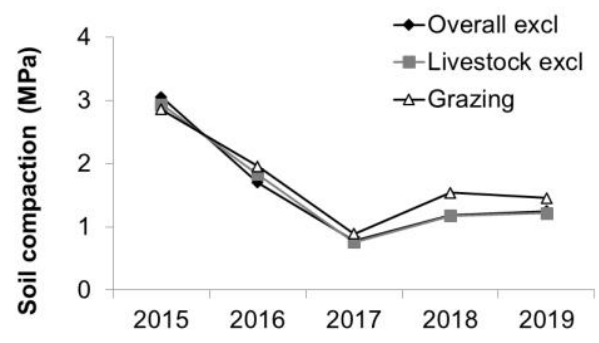

(a)

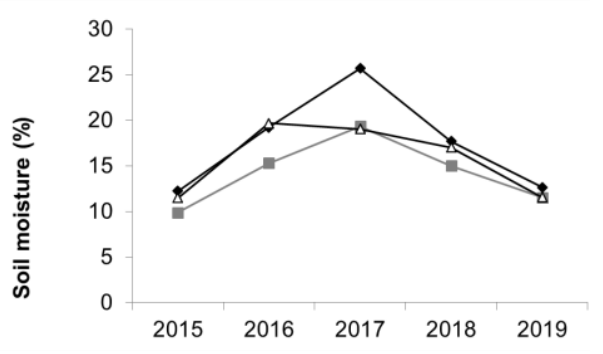

(b)

Figure 1. Recording of soil conditions along sampling years: (a) Soil compaction (resistance to penetration); (b) mean soil moisture.

Seedling density was different between the two study sites (farms) since the beginning of study. Pirinaica farm triplicate the number of seedlings compared to Rolito farm (Table 1). In 2019, after five growing seasons, the differences among study sites were similar, but the rate of height growth were quite similar between sites.

The exclusion treatment favored the natural tree regeneration by reducing browsing pressure while increasing seedling growth rate (Table 1). The effect of animal exclusion did not modified the 
initial differences among treatments: high seedling density in overall exclusions, intermediate values in the livestock exclusions and lower values in the grazing (control) area (Table 1). In terms of change rates, the seedling density remained similar within the fences, with slight increases from 2015 to 2019 ( $29 \%$ in overall exclusions and $38 \%$ in livestock exclusions). While in the grazed area (control) the mean seedling density also maintained similar values with a slight decrease $(-5 \%)$. On the other hand, the seedlings height changed positively in all sites and treatments from 2015 to 2019, but the effect of exclusion treatment was statistically significant (Table 1).

Table 1. Seedling density $\left(\mathrm{m}^{2}\right)$ at the beginning (2015) and the end of monitoring (2019), and mean annual height growth $(\mathrm{cm})$ according to study site (farm) and animal exclusion treatment.

\begin{tabular}{ccccc}
\hline & & $\mathbf{2 0 1 5}$ & $\mathbf{2 0 1 9}$ & $\Delta$ annual growth \\
\hline Site & Pirinaica & $12.1 \mathrm{~b}$ & $16.2 \mathrm{~b}$ & 0.88 \\
& Rolito & $4.6 \mathrm{a}$ & $5.1 \mathrm{a}$ & 1.45 \\
$\mathrm{~F}(\mathrm{p})$ & & $3.55(0.011)$ & $5.23(0.026)$ & $0.82(0.370)$ \\
\hline Exclusion & Overall & $16.6 \mathrm{~b}$ & $21.3 \mathrm{~b}$ & $2.28 \mathrm{~b}$ \\
& Livestock & $4.2 \mathrm{a}$ & $5.8 \mathrm{a}$ & $0.83 \mathrm{ab}$ \\
& Grazing & $4.1 \mathrm{a}$ & $3.9 \mathrm{a}$ & $0.39 \mathrm{a}$ \\
$\mathrm{F}(\mathrm{p})$ & & $4.24(0.019)$ & $3.74(0.032)$ & $3.30(0.044)$ \\
Interaction F $(\mathrm{p})$ & & $2.21(0.119)$ & $1.36(0.265)$ & $0.05(0.955)$ \\
\hline
\end{tabular}

Different letters in each column indicate significant $(\mathrm{p}<0.05)$.

Browsing damage as well as drought damage (apical desiccation) were variable among years (Fig. 2a), but some years the accumulated effect of both damages accumulated almost $40 \%$ of damage on tree regeneration, mainly in the grazed area. As we expected, browsing damage was significantly reduced by the exclusion treatments $(\mathrm{F}=6.41, \mathrm{p}=0.008)$ which also explain the differences of the height growth described before. But contrary to what we expected, seedling survival was not affected by animal exclusion ( $\mathrm{F}=1.44, \mathrm{p}=0.248$ ) which ranged from $87 \%$ in overall exclusion, $76 \%$ in livestock exclusion and $68 \%$ in the grazing area, from 2015 to 2019 (Fig. 2b). This could be due to the regrowth ability of $N$. antarctica that allows it to recover after the loss of aerial biomass generated by browsing. Also, it could be due to internal variability of data. However, seedling survival was conditioned by seedling age as early ages ( 2 and 3 years old) (Fig. $2 b$ ), which has been recognized as the age most susceptible to damage in various forest species.

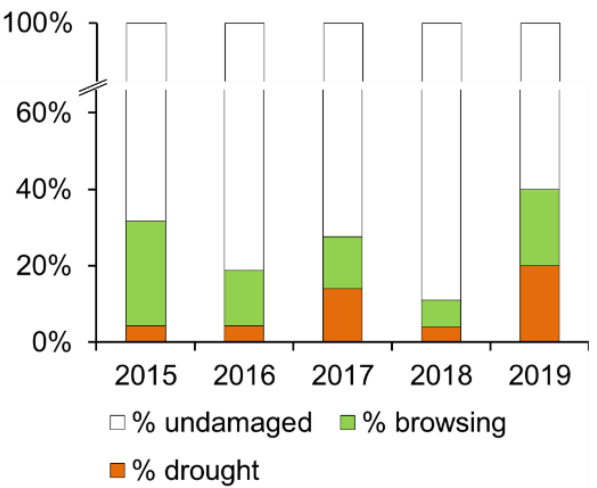

(a)

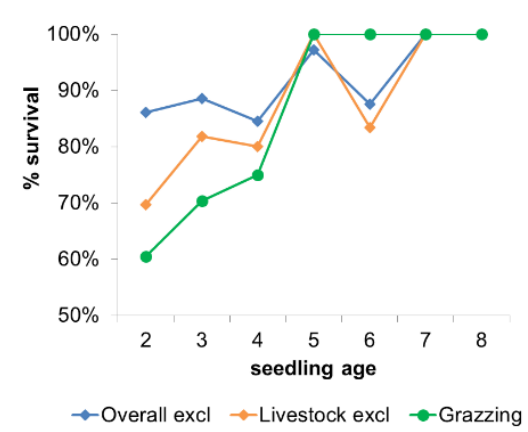

(b)

Figure 2. Proportion of (a) damage on tree seedlings; and (b) seedlings survival according to age, in the different exclusion treatments (overall, livestock, and grazing or control).

Based on our results, the use of exclusions to manipulate the impact of browsing favored the growth rate of tree regeneration -and likely the future architecture of trees- but the survival of individuals only improved at the ages most sensitive to this impact. The accumulated damages due to the climate in some years accentuate those of herbivory. 
Regarding understory composition, the exclusion treatments did not affect the species richness $(\mathrm{F}=1.187, \mathrm{p}=0.306)$, which varied from between 13-14 species per plot (Fig. 3a). The total vegetation cover varied among treatments $(\mathrm{F}=13.85, \mathrm{p}<0.001)$ and years $(\mathrm{F}=3.23, \mathrm{p}=0.023)$, increasing with time and within the overall exclusion compared to the other two situations (Fig. 3b). Dictos cover (Fig. 3c) remained similar among treatments $(F=0.591, p=0.554)$ and years $(F=1.572, p=0.196)$, but monocots cover (Fig. 3d) increased over time $(F=5.08, p=0.002)$, mainly in the exclusion treatments compared to the grazed area $(\mathrm{F}=7.93, \mathrm{p}<0.001)$. Ferns were only affected by the exclusion treatments $(\mathrm{F}=3.13, \mathrm{p}=0.045)$, increasing significantly in fenced compared to grazed plots (Fig. 3d).

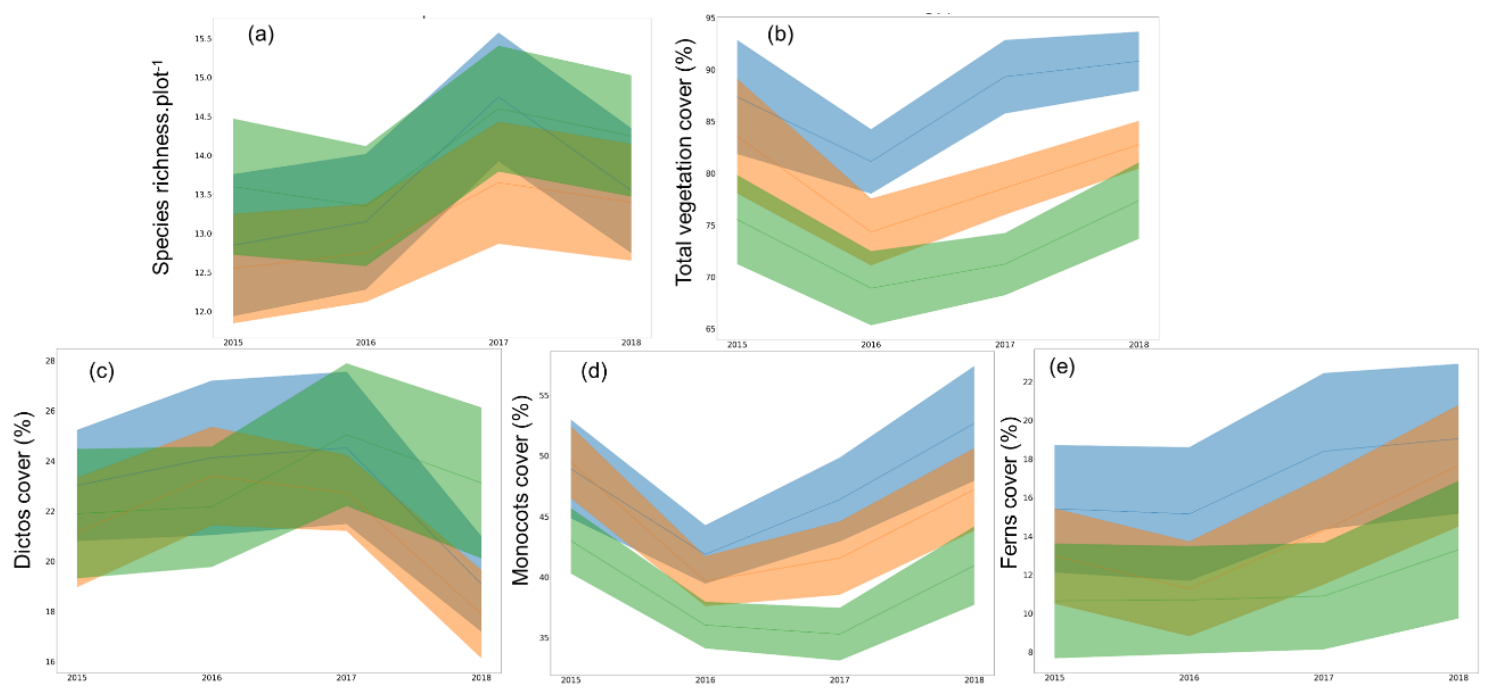

Figure 3. Understorey variables along the sampling years: species richness, total vegetation cover and cover of forbs (dicots), grasses (monocots) and ferns, according the animal exclusion treatment (blue $=$ overall exclusion, orange $=$ livestock exclusion, and green $=$ grazing area) .

The average height of the understory doubled in height from $2015(15-20 \mathrm{~cm})$ to $2019(25-30 \mathrm{~cm})$, while some years (2018) reached higher values $(31-48 \mathrm{~cm}$ ) (Fig. 5). Meanwhile, the height of tree regeneration (initial stage) did not exceed $15 \mathrm{~cm}$. Moreover, some plants, and especially palatable herbs (e.g., Taraxacum sp., Osmorhiza sp.) and grasses (e.g., Agrostis sp., Bromus unioloides) increased much more in abundance and height than ñire seedlings within fences.

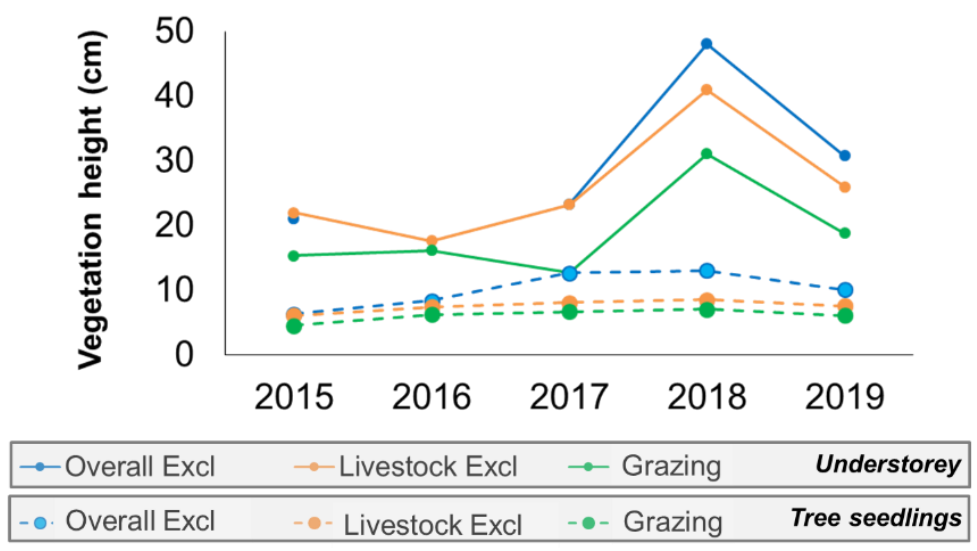

Figure 5. Height of vascular plants (vegetation) and tree seedlings in the different exclusion treatments (overall, livestock and grazing = without exclusion).

Based on our results, the use of large exclusions in Nothofagus forests greatly benefited to the cover and biomass of vascular plants in the understorey. Long-term negative effect to tree regeneration could likely due to competitive interactions mainly with grasses species. Individual 
closures could be more efficient [9], but the cost-benefit of such interventions needs to be evaluated to implement in SPSs.

In the future, the evaluation of the differential impact of seasonal livestock use (spring-summer vs. autumn-winter) of forest could be useful to define specific patterns of animal movement that reduce tree damage while maintain competitive effects at minimum.

\section{References}

1. Edenius, L.; Bergman, M.; Ericsson, G.; Danell, K. The role of moose as a disturbance factor in managed boreal forests. Silva Fenn. 2002, 36(1), 57-67.

2. Cingolani, A.M.; Noy-Meir, I.; Renison, D.; Cabido, M. La ganadería extensiva, ¿es compatible con la conservación de la biodiversidad y los suelos? Ecol Austral. 2008, 18, 253 - 271.

3. Cherif, M.; Loreau, M. Plant-herbivore-decomposer stoichiometric mismatches and nutrient cycling in ecosystems. Proc R Soc B. 2013, 280, 20122453.

4. Lehmkuhler, J.W.; Felton, E.E.D.; Schmidt, D.A.; Bader, K.J.; Garrett, H.E; Kerley, M.S. Tree protection methods during the silvopastoral-system establishment in midwestern USA: cattle performance and tree damage. Agrofor Syst. 2003, 59, 35-42.

5. Allcock, K.G.; Hik, D.S. Survival, growth and escape from herbivory are determined by habitat and herbivore species for three Australian woodland plants. Oecologia. 2004, 138, 231-241.

6. Traba, J.; Iranzo, E.; Carmona, C.; Malo, J.; Realised niche changes in a native herbivore assemblage associated with the presence of livestock. Oikos. 2017, 126, 1400-9

7. Bernes, C.; Macura, B.; Jonsson, B.G.; Junninen, K.; Müller, J.; Sandström, J.; Lõhmus, A.; Macdonald, E. Manipulating ungulate herbivory in temperate and boreal forests: effects on vegetation and invertebrates. A systematic review. Environ Evid. 2018, 7,13. https://doi.org/10.1186/s13750-018-0125-3

8. Ormaechea, S.; Peri, P.L. Landscape heterogeneity influences on sheep habits under extensive grazing management in Southern Patagonia. Livestock Research for Rural Development. 2015, 26(5), 105.

9. Peri, P.L.; Bahamonde, H.A.; Lencinas, M.V.; Gargaglione, V.; Soler, R.M.; Ormaechea, S.; Martínez Pastur, G. A review of silvopastoral systems in native forests of Nothofagus antarctica in southern Patagonia, Argentina. Agrof Syst. 2016, 90(6), 933-960.

10. Brancaleoni, L.; Strelin, J.; Gerdol, R. Relationships between geomorphology and vegetation patterns in subantarctic Andean tundra of Tierra del Fuego. Polar Biol. 2003, 26, 404-410

11. Mestre, L.; Toro-Manríquez, M.; Soler, R.; Huertas-Herrera, A.; Martínez Pastur, G.; Lencinas, M.V. The influence of canopy-layer composition on understory plant diversity in southern temperate forests. For Ecosys. 2017, 4:6, https://doi.org/10.1186/s40663-017-0093-z

12. Godefroid, S.; Koedam, N. Interspecific variation in soil compaction sensitivity among forest floor species. Biol Conserv. 2004, 119, 207-217. 